\title{
PRESENÇA OSWALDIANA NO TEATRO ESTÁDIO DE JOSÉ CELSO MARTINEZ CORRÊA: ANTROPOFAGIA, MESTIÇAGEM CULTURAL, TERREIRO ELETRÔNICO
}

\author{
Nanci de Freitas ${ }^{1}$
}

Resumo

O artigo analisa as formas adotadas na construção do Teatro Oficina, de São Paulo, e a proposta de ampliação do espaço em um Teatro Estádio, à maneira "greco-tropical", como diz José Celso Martinez Corrêa, diretor do Teatro Oficina Uzyna Uzona. O projeto, inspirado no manifesto de Oswald de Andrade, Do teatro que é bom..., retoma questões da antropofagia para a contemporaneidade, propondo a criação de um "terreiro eletrônico", espaço de reinvenção do teatro e de sua recepção, buscando a comunhão com o público.

Palavras-chave: Teatro Oficina, Teatro Estádio, José Celso Martinez Corrêa, Oswald de Andrade, antropofagia.

Abstract

The article examines the architectural forms adopted in the construction of the Theatre Workshop, in São Paulo, and the proposed extension of the space into a Theatre Stadium, in a "tropical-Greek" way, according to José Celso Martinez Corrêa, director of the company Teatro Oficina Uzyna Uzona. The project, inspired by the manifesto of Oswald de Andrade, About the good theatre..., takes up issues of the antropophagy movement for the present time, proposing the creation of an "electronic yard", a space for the reinvention of theatre as well as its reception by seeking communion with the public.

Keywords: Theatre Workshop; Stadium Theater, José Celso Martinez Corrêa, Oswald de Andrade, anthropophagy. 
Teatro Oficina: uma ágora antropofágica

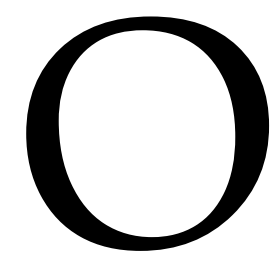
encenador José Celso Martinez Corrêa, cuja trajetória artística receberia influência de artistas e pensadores como Sartre, Artaud, Brecht, Nelson Rodrigues, Beckett e Nietzsche, seria, sobretudo, em suas próprias palavras, um oswaldiano, incorporando em seu trabalho o pensamento antropofágico de Oswald de Andrade como leitura da gênese e do ethos da cultura brasileira. Afirma José Celso:

O primeiro ato global do que chamamos Brasil foi a primeira missa, teatro português prá índio ver. Os índios viram. Trinta e poucos anos depois, corpos nus dos Caetés, encontraram carne em baixo das saias dos figurinos eclesiásticos do hemisfério norte naufragando nos mares temperamentais dos recifes. Foi o segundo ato, os Caetés, literalmente, descobriram o teatro global do hemisfério sul com a devoração de Sardinha, bispo português. O deus Dioniso re-estreou no Brasil, no litoral de Alagoas, a mesma cena primeira e última da origem e fim da tragédia grega: a devoração de Pentheu pelas Bacantes. Oswald de Andrade como um Ésquilo, retomou este ato, como mito de origem da civilização brazyleira. $\mathrm{O}$ teatro Oficina, tataraneto de Gil Vicente, amante de Martins Pena, neto do Vestido de Noiva, filho do TBC e do Arena, teve seu segundo nascimento com $\mathrm{O}$ rei da vela. Oswald resignando o teatro brasileiro. Ao dilema hamletiano do mundo ocidental cristão "to be or not to be", respondeu "yes, tupy", plugando tecnizado o retorno do mundo bárbaro americano asiano africano. O lugar deste retorno foi o Teatro Oficina. ${ }^{2}$

1 Professora adjunta no Instituto de Artes da Universidade do Estado do Rio de Janeiro - UERJ e doutora em teatro pela UNIRIO. Atua na área de artes cênicas como diretora e pesquisadora. Na UERJ, coordena o projeto Mirateatro! Espaço de estudos e criação cênica.

2 Fragmento do texto de José Celso Martinez Corrêa, Teatro Oficina osso duro de roer. In: Teatro Oficina: Lina Bo Bardi/ Edson Elito. São Paulo, Brasil, 1980-1984. Textos: Lina Bo Bardi, Edson Elito e José Celso Martinez Corrêa. Lisboa: Editorial Blau; Instituto Lina Bo Bardi e P.M. Bardi, 1999. As páginas da publicação não são numeradas.
A partir da lendária montagem da peça $O$ rei da vela, de Oswald de Andrade, realizada pelo Teatro Oficina, em 1967, em São Paulo, a relação entre o pensamento artístico oswaldiano e a prática teatral de José Celso Martinez Corrêa (que chegou a se dizer "o cavalo oswaldiano da cultura brasileira") é sempre anunciada em declarações e entrevistas do encenador. Em matéria publicada no jornal Folha de São Paulo, por ocasião das celebrações do cinquentenário de morte de Oswald de Andrade, em 2004, José Celso afirma que sua vida se dividiu em a.O, d.O: "A partir de Oswald, tudo o que fiz foi influenciado por ele. Oswald foi meu Shakespeare, meu Goethe, me trouxe a chave para toda a cultura brasileira". ${ }^{3} \mathrm{Na}$ mesma data, em entrevista concedida ao jornal $O$ Globo, o diretor do Teatro Oficina enaltece o mestre modernista e a originalidade do pensamento antropofágico:

\begin{abstract}
Oswald será ainda reconhecido pelo mundo como um dos grandes homens do século XX. E continua nos devorando. Foi o primeiro pós-moderno, como ele mesmo disse nos anos 20. Ele viu que o mundo acabaria por se tornar um lugar movido pela antropofagia. Tudo que se chama de mix, tudo o que se vê de imigração que contorna cidades e devora a cultura ocidental, é a própria cultura, que está comendo e vai comer o mundo. Os povos devoram e vomitam o moralismo, a noção do bem e do mal, da cultura puritana, as utopias, as igrejas. A coisa não é mais ser socialista ou ir para o céu. Não existe messias, só devoração. ${ }^{4}$
\end{abstract}

O Teatro Oficina, localizado na Rua Jaceguay, 520, no Bairro do Bexiga, em São Paulo, abriga uma trajetória de resistência política/ética/poética ao sistema teatral burguês e ao mercado do entretenimento, praticando um teatro que é pura relação entre arte e vida. Resistência que se sustenta

3 MACHADO, Elek. 50 anos da morte de Oswald de Andrade. Folha de São Paulo, 22 de outubro de 2004, llustrada, página: E4.

4 "O mundo come Oswald" é o título da entrevista que José Celso Martinez Corrêa concedeu ao jornalista Arnaldo Bloch. Ver: "Segundo Caderno", página 1, O Globo, Rio de Janeiro, 22 de outubro de 2004. 
nas ideias e ações do encenador, José Celso Martinez Corrêa, que vem lutando, desde os anos 1980, para concretizar o ambicioso projeto do Teatro Estádio. Trata-se da ampliação do espaço físico do Teatro Oficina, já prevista nos primeiros estudos dos arquitetos Lina Bo Bardi (19141992) e Edson Elito, responsáveis pelo formato atual do teatro. Com a expansão das atividades do Grupo Oficina e de sua interseção com a comunidade do Bairro Bexiga, teria surgido, segundo José Celso, "a necessidade de uma arquitetura virando teatro, que vira urbanismo que chega na construção de uma Ágora, de uma praça pública. Arqueologia urbana, não é Lina?". ${ }^{5}$

A casa de espetáculo ocupada pela trupe do Oficina, a partir de 1958, passou por um incêndio, em 1966, sendo reconstruída por Flávio Império e Rodrigo Lafévre, e chegaria ao tombamento como patrimônio público estadual, em 1981, com o apoio massivo da classe teatral. [Ali haviam sido realizadas as históricas montagens de $\mathrm{O}$ rei da vela, Roda Viva e Galileu Galilei.] Nesse momento, Lina Bo Bardi - que já havia projetado, no espaço, os cenários para os espetáculos Gracias Senhor e $\mathrm{Na}$ selva das cidades - realizou, ao lado de Marcelo Suzuki, os primeiros estudos para uma reforma do teatro, que não chegou a ser concretizada. Em 1984, Edson Elito se juntaria à arquiteta Lina Bo Bardi para a realização do projeto do teatro, configurado em seu formato atual.

"Uma rua chamada teatro", como Edson Elito definiu a casa de espetáculos, construída em uma rua sem saída, ganharia a forma de uma passarela, com o "palco" ocupando todo o espaço do teatro da porta de entrada até o paredão, ao fundo. Neste, dois arcos, lembrando pórticos romanos, sugerem o desejo de abertura para além do espaço delimitado. Para o público, três arquibancadas desmontáveis, de estrutura metálica, com altura progressiva do pé direito chegando a 13 metros, compondo as galerias laterais da passarela e justapostas

5 Fragmento do texto de José Celso Martinez Corrêa, conforme op. cit. nota $\mathrm{n}^{\circ} 01$. às paredes de grandes tijolos, do início do século. O chão de terra foi coberto por pranchas de madeira desmontáveis. Em sua totalidade, o projeto foi realizado para atender ao desejo de José Celso de referendar os quatro elementos da natureza. O teto foi planejado visando "uma cobertura em abóbada de aço deslizante, que, platonicamente, contempla o elemento ar, assim como o jardim existente, a terra". Para introduzir a água e o fogo no espaço, foram elaborados sistemas complexos: "projetamos uma cachoeira composta por sete tubos aparentes que deságuam em um espelho d'água como mecanismo de re-circulação. (...) Para o fogo foi prevista uma rede de gás que abastece um ponto no centro geométrico do teatro", diz o arquiteto Edson Elito.

A criação do projeto teria sido marcada por confluência (às vezes tensa) entre a formação modernista dos arquitetos, com sua preferência pela pureza dos elementos e pelo racionalismo construtivo, e a concepção teatral de José Celso, "com o simbolismo, a iconoclastia, o barroco, a antropofagia, o sentido, a emoção e o desejo de contato físico entre atores e plateia", aspectos desenvolvidos no seu "te-ato", explica Edson Elito. Contudo, o resultado foi um espaço cênico unificado e dotado de modernos recursos de som e iluminação, além de um sistema de captação e distribuição de imagens de vídeo para todo o teatro, numa concepção que permite a simultaneidade de ações em locais distintos. Unindo dispositivos técnicos contemporâneos ao despojamento do "terreiro eletrônico", local de atuação dos "bárbaros tecnizados", o teatro apresenta uma estrutura com flexibilidade de uso, em que "todo o espaço é cênico", deixando à vista os equipamentos e objetos de cena, fazendo interagir atores, técnicos e público, que "comungam ou se contrapõem e não há como esconder nenhum deles. Todos participam da cena". ${ }^{6}$ A definição de Lina Bo Bardi para o espaço é sucinta:

6 Texto de Edson Elito. op. cit. nota 1. Páginas sem numeração. 
Do ponto de vista da arquitetura, o Oficina vai procurar a verdadeira significação do teatro - sua estrutura física e táctil, sua não-abstração - que o diferencia profundamente do cinema e da tevê, permitindo ao mesmo tempo o uso total desses meios. (...) $\mathrm{Na}$ base da maior simplicidade e da maior atenção aos meios científicos da comunicação contemporânea. É tudo. Olhar eletronicamente, sentados numa cadeira de igreja. ${ }^{7}$

Para José Celso Martinez Corrêa, diretor da companhia Teatro Oficina Uzyna Uzona (como passou a se chamar o Grupo Oficina), o teatro é "uma metáfora arquitetônica e urbana de uma postura diante do teatro e do espetáculo do mundo", funcionando como um barracão de escola de samba, lugar das práticas diárias de construção do trabalho artístico. A horizontalidade de sua configuração espacial lembra o sambódromo, onde "reina a monarquia, governo de Momo, o carnaval permanente que desfila comendo solto na pista em busca de sua apoteose, servindo banquetes periódicos seguidos de grande seca". Neste lugar, proclama o encenador: "Muitas noites, cenas são dadas como carne viva a pequenas multidões antropófagas, produzindo mirações desta obra coletiva de arte que às vezes é o Teatro Oficina. Então lêem-se marcas passadas e chaves futuras da história recente do Brasil lá tatuadas como uma caverna programada".

\section{O Teatro Estádio e as "ideias teatrais" de Oswald de Andrade}

As formas adotadas na construção do Teatro Oficina e a proposta de ampliação do espaço em um Teatro Estádio, à maneira "greco-tropical", segundo José Celso Martinez Corrêa, foram inspiradas no manifesto de Oswald de Andrade, “Do teatro que é bom...". Trata-se de um artigo

7 Texto de Lina Bo Bardi, com o título "Teatro Oficina". Ibid. páginas sem numeração.

8 Conforme texto de José Celso Martinez Corrêa. Ibid. páginas sem numeração. publicado em Ponta de Lança, em 1943, ${ }^{9}$ no qual o escritor modernista apresenta uma síntese de suas "ideias teatrais", marcando uma posição estética dentro do panorama cênico moderno. Na forma de debate entre dois interlocutores, Oswald coloca em confronto o "teatro de câmara" e o "teatro para as massas", utilizando-se da própria condição dialógica da estrutura dramática para marcar a relação entre os "personagens", que se opõem numa dialética de discurso/resposta.

O diálogo circunscreve as divergências entre Oswald de Andrade e um porta-voz do Grupo Universitário de Teatro - GUT, grupo paulista que atuou nos anos quarenta sob a direção do crítico Décio de Almeida Prado, tendo recusado a proposta do autor de $O$ rei da vela para a montagem de seu texto. Os integrantes do GUT (Lourival Gomes Machado, Clóvis Graciano, além de Décio de Almeida Prado) participaram também da revista Clima, redigida entre 1941 e 1944, ao lado de Antonio Candido, Paulo Emílio Salles Gomes e Rui Coelho, apelidados por Oswald de Andrade de "chato-boys". O grupo foi alvo preferido dos ataques do escritor modernista, nesse período, principalmente depois dos juízos críticos formulados por Antonio Candido à obra ficcional de Oswald, no ensaio "Estouro e Libertação", 10 no qual fez restrições ao livro $A$ revolução melancólica, primeiro volume do ciclo Marco Zero, publicado em 1943. Oswald respondeu ferozmente a Antonio Candido em seu artigo, "Antes do Marco Zero" (publicado também em Ponta de Lança), rompendo assim com o grupo de Clima. O embate refletiria um novo momento na produção

9 ANDRADE, Oswald. Do teatro que é bom.... In: Ponta de Lança. São Paulo: Ed. Globo, 1991. p.102-108. O livro reúne artigos publicados, em 1943, nos jornais, Estado de São Paulo, Diário de São Paulo e na Folha da Manhã e três conferências escritas em 1943/44.

10 CANDIDO, Antonio. Estouro e libertação. In: Brigada Ligeira. São Paulo: Ed. UNESP, 1992, p.17-32. Segundo o autor, o texto, publicado em 1945, fora escrito em 1944, ampliando três artigos de 1943, escritos para o rodapé semanal de crítica da Folha da Manhã. Ver comentário no artigo Digressão sentimental sobre Oswald de Andrade. In: Candido, Antonio. Vários escritos. São Paulo: Ed. Pensamento, 1970. 
e no pensamento artístico brasileiro, marcando as oposições entre a crítica erudita praticada pelos modernistas e uma nova crítica especializada que surgia da geração emergente dos cursos de ciências sociais da USP, a partir de 1942, tendendo à especialização. ${ }^{11}$

O debate deixa claras as divergências, no campo ideológico, quanto à função do teatro. De um lado, as experiências cênicas camerísticas tendem a um aprimoramento formal em busca de uma recepção intimista, enquanto a posição oposta defende uma reforma do espetáculo, tendo em mente o teatro como fenômeno social, dirigido às massas, capaz de agregar elementos do cinema e dos esportes, como nas montagens teatrais russas, em particular as encenações de Meyerhold. ${ }^{12}$

O "teatro de câmara", iniciado pelo teatro intimista de August Strindberg, aparece na discussão numa aproximação com as ideias do encenador francês, Jacques Copeau, desenvolvidas a partir de sua atuação no Théâtre du Vieux Colombier, iniciada em 1913, e com o teatro moderno italiano, divulgado, principalmente, a partir da dramaturgia de Luigi Pirandello e das experiências cênicas de Anton Giulio Bragaglia.São tendências do teatro europeu que exerceram influência sobre o processo de modernização da cena brasileira, em especial na década de 1940.

No texto/manifesto de Oswald de Andrade, "Do teatro que é bom...", o defensor do teatro de câmara insiste na importância de se espelhar no teatro moderno da França, nas encenações de Jacques Copeau e Louis Jouvet, como também nos textos de Jules Romains e de Giraudoux:

11 Ver: BERNSTEIN, Ana. A crítica cúmplice: Décio de Almeida Prado e a formação do teatro moderno. São Paulo: Instituto Moreira Salles, 2005. p. 59-72. Para situar Oswald, nesse debate, ver: SANTIAGO, Silviano. Sobre plataformas e testamentos. In: Ponta de Lança. 1991, p. 7-22.

12 Uma análise minuciosa do manifesto "Do teatro que é bom..., de Oswald de Andrade, pode ser conferida em artigo de minha autoria, intitulado: "A poética teatral de Oswald de Andrade e a polêmica em torno do 'teatro de câmara' e do "teatro para as massas". In: Revista Concinnitas. arte, cultura e pensamento. V.6, p. 96-129. Rio de Janeiro: Instituto de Artes da UERJ, 2004. www.concinnitas.uerj
Uma reação admirável contra o abastardamento trazido pelo cinema. Sentindo-se atacado, o teatro melhorou, produziu o Vieux Colombier, o Atelier, alguns minúsculos palcos de escol, onde se refugiou o espírito nessa fabulosa Paris que a bota imunda do guarda-floresta Hitler tenta inutilmente pisar... Veja como graças aos Dullin, aos Pitoëff, aos Copeau, o teatro soube reacender a sua flama que parecia extinta... (ANDRADE, 1991, p.103). ${ }^{13}$

O discurso do segundo interlocutor reflete a postura ideológica de Oswald de Andrade, intelectual - temporariamente - engajado ao Partido Comunista. O tom idealista enfatiza a utopia de um mundo novo socialista, no qual as artes eos esportes, integrados aos meios de comunicação e aos avanços tecnológicos, cumpririam um papel decisivo na educação e na luta contra as forças nazifascistas, imperiosas naquele momento da Segunda Guerra Mundial, em 1943, quando o escritor publicava seu manifesto. Diz Oswald, fazendo ressalvas ao teatro de câmara: "Se amanhã se unificarem os meios de produção, o que parece possível, já não haverá dificuldades em reeducar o mundo, através da tela e do rádio, do teatro de choque e do estádio. É a era da máquina que atinge o seu zênite". (Ibid.: 102/103).

A configuração do projeto teatral oswaldiano, enquanto espetáculo de estádio, parece se pautar nas imagens das grandes tradições populares (o teatro grego, os mistérios medievais e o teatro de Shakespeare), justapostas aos modernos espetáculos que ele pôde assistir na Paris dos anos 1920, como as produções cênicas russas, desencadeadas pela cultura da Revolução de Outubro (inclusive os balés de Diaghilev). Conforme reitera seu texto, as experiências modernas indicam "o aparelhamento que a era da máquina, com o populismo do Stravinski, as locomotivas de Poulenc, as metralhadoras de Shostakovich na música, a arquitetura monumental de Fernand Léger e a encenação de Meyerhold,

13 Andrade, Oswald. Do teatro que é bom.... In: Ponta de Lança. São Paulo: Ed. Globo, 1991. Pag.:102-108. 
propõe aos estádios de nossa época". No teatro de estádio, "há de se tornar uma realidade o teatro de amanhã, como foi o teatro na Grécia, o teatro para a vontade do povo e a emoção do povo..." (Ibid.: 107). ${ }^{14}$

Onexo dessa discussão está relacionado ao processo de secularização do teatro e à sua progressiva profissionalização, que iriam empobrecer a possibilidade de jogo, com a diluição de seu caráter comunitário e sua intensa inserção nas atividades de lazer da burguesia. $\mathrm{O}$ abandono dos espaços teatrais abertos, a partir do século XVI, iria determinar a convencionalização do teatro no palco italiano, resultando em sua consequente perda de ludicidade. ${ }^{15} \mathrm{Com}$ a vitória do individualismo, assim como a pintura mural abandonaria as paredes das igrejas para se fixar no cavalete, "o teatro deixou o seu sentido inicial que era o de espetáculo popular e educativo, para se tornar um minarete de paixões pessoais, uma simples magnésia para as dispepsias mentais dos burgueses bem jantados", diz Oswald de Andrade. (Ibid.: 104).

José Celso Martinez Corrêa acredita que a estrutura cênica sugerida por algumas obras dramatúrgicas deOswald de Andrade apontam para a ideia do Teatro Estádio, como a peça $O$ homem e o cavalo, que teve uma leitura-espetáculo dirigida por ele, em 1985, no Teatro Sérgio Cardoso, com a participação de 150 pessoas, e também Os mistérios gozosos, espetáculo montado em 1982, para a comemoração do tombamento do Teatro Oficina. Na verdade, diz José Celso, o projeto artístico do Teatro Oficina seria um resultado concreto de toda a dramaturgia de Oswald de Andrade, cujo centenário de nascimento (em 1990) foi celebrado com a encenação de um Banquete Antropofágico no canteiro de obras do Teatro

14 Essa noção de "espetáculo de arte total", originária das concepções wagnerianas, foi disseminada nos debates estéticos das primeiras décadas do século $X X$ e nas experimentações de encenadores como Gordon Craig, Adolphe Appia, Max Reinhardt, Erwin Piscator, e nas concepções espaciais de Walter Gropius, na Bauhaus, guardadas as diferenças entre essas concepções cênicas.

15 Sobre esse tema da progressiva perda do elemento lúdico na arte, ver o livro de Huizinga, Johan. Homo Ludens. Tradução de João Paulo Monteiro. São Paulo: Perspectiva, 1999.
Oficina e cujo cinquentenário de morte (em 22 de outubro de 2004) teve como homenagem o que se chamou de Devoração de Oswald Devorado Devorando-nos. ${ }^{16}$

A montagem de Mistérios Gozosos teria sido, afirma o encenador, "uma sessão de terreiro eletrônico, vídeo transmissão da 'sala branca' da orgia de Oswald, com 'sexo explícito', como se diz". Foi aí que teria surgido a ideia da passarela para os coros de As Bacantes e do Mangue, onde ocorrem as ações de Os mistérios Gozosos:

As personagens das putas e dos michês exigiram a rua do Mangue. Abaixo a arquibancada decontemplação. Queviesse o canal do Mangue, passarela de escola de samba. O homem e o cavalo, de Oswald, também queria o Teatro de Estádio. Quebrar paredes, entrar luz natural, sair da caixa preta. Espaço urbano. Cosmos. Teto aberto pro céu da encruzilhada do hemisfério sul. Terra de canteiro, água de cachoeira. E todas as tecnologias. ${ }^{17}$

O projeto monumental do Teatro Estádiofoiretomado,posteriormente, pelos arquitetos João Batista Martinez Corrêa ${ }^{18} \mathrm{e}$ Beatriz Pimenta Corrêa, respectivamente irmão e sobrinha do diretor. José Celso Martinez Corrêa, que encenou Os sertões, uma série de cinco espetáculos a partir de adaptação da obra de Euclides da Cunha, diria em entrevista ao Jornal do Brasil, no dia 3 de fevereiro de 2006, a propósito da última versão do Teatro Estádio: “Fomos

16 Na programação do evento, segundo a divulgação da Folha de São Paulo, teria ocorrido o lançamento da "Primeira Versão do Programa de Arquitetura-Urbanismo e Gestão do Teatro Estádio" e a leitura de A luta, adaptação de trecho de Os Sertões, de Euclides da Cunha. Ver o documento mencionado no site do Teatro Oficina, no site: www.teatrooficina.uol.com.br

17 Corrêa, José Celso Martinez. Op. cit. nota 1, sem numeração de página. Mistérios Gozosos foi uma montagem teatral a partir do poema dramático de Oswald de Andrade, intitulado $O$ Santeiro do Mangue: Mistério gozoso em forma de Ópera. Ver outros comentários sobre o espetáculo em entrevista concedida por José Celso Martinez Corrêa à revista, Caros Amigos, na edição de aniversário de sete anos. Figurando como matéria de capa, a entrevista com o título: "Zé Conselheiro" está nas páginas 31 a 37 . A matéria aborda também a discussão sobre a construção do Teatro Estádio e a luta do encenador com Silvio Santos.

18 João Batista Martinez Corrêa é o autor do projeto da estação de metrô Cardeal Arcoverde, em Copacabana, no Rio de Janeiro. 
influenciados pela paisagem de Cocorobó descrita em Os sertões, nos caminhos e montanhas. E apostamos nas curvas de nível. Queremos um teatro rebolante, que pode ser trabalhado por dentro e por fora. Que deveria ter 15 mil lugares, mas pode ter 7, 6, 5 mil...". O conglomerado teatral, de ambições sócio-culturais, prevê também a construção do que o encenador chama Universidade Brazyleira (sic) de Cultura Antropofágica de Mestiçagem Multimídia, voltada para a formação de atores, "uma escola com princípios baseados nas teses de Oswald de Andrade rejeitadas pela USP, uma escola em que a educação se mescle com saúde, tecnologia e inclusão", afirma o encenador. ${ }^{19}$

Em matéria especial de capa na revista Bravo, de março de 2005, José Celso falando da montagem de Os sertões, de Euclides da Cunha, explicitaria, assim, o sentido do Teatro Estádio:

Eu acho que este teatro, da multidão, é o mais forte do mundo em todos os tempos. Estamos na iminência de chegar aqui onde chegou o teatro grego - até mesmo ultrapassá-lo -, onde chegou Shakespeare. Estamos a ponto de criar um teatro realmente popular, carnavalesco, orgiástico, um teatro total com toda essa cultura da mestiçagem, antropofágica, que, num certo sentido, tende a ser hegemônica no mundo. Ela tem uma riqueza que a cultura do capitalismo - puritana do bem e do mal, do palco italiano, do convencional - não tem. E essa é uma luta que se confunde com a luta de quebrar os cânones que separam a arte do povo. Que o teatro saia da gaiola do pensamento decadente e que se ligue à multidão, criando uma coisa tão forte quanto à música popular, o cinema, o futebol, a arte de viver do povo brasileiro. Também é uma luta de transformação do próprio espaço cênico, que precisa se misturar com vídeo, música, dança e artes plásticas. ${ }^{20}$

19 Entrevista publicada no Jornal do Brasil, em 3 de fevereiro de 2006. Caderno B, páginas: B1 e B2.

20 Revista Bravo, março de 2005. Páginas: 26-35. Além de entrevista com José Celso Martinez Corrêa, a matéria apresentadiversos comentários sobreotrabalhodoencenador, feitos por artistas e críticos, tais como: Helio Ponciano, Renato Borghi, Sérgio Carvalho, Sérgio Augusto de Andrade.

\section{A terra e a luta: terreiro eletrônico $x$ baú da felicidade.}

O projeto de construção do Teatro Estádio inclui a ampliação do espaço do Teatro Oficina, desembocando numa apoteose, uma espécie de praça pública apta a abrigar espetáculos para grandes plateias e realizar programas de formação artística e inclusão social. ${ }^{21}$ Projeto que esbarra num paredão que separa o teatro de um estacionamento que pertence ao Grupo Sílvio Santos, no qual foi planejada a construção de um shopping center tradicional. Diz José Celso: "A palavra mágica do Teatro é MERDA. A tripa da Jaceguay 520 não tem cu. A saída da matéria do amor feito, estaca num beco, num estacionamento do Baú da Felicidade" ${ }^{22}$

As inúmeras tentativas de intermediação com o Grupo Sílvio Santos, no sentido de convencimento acerca da importância social do Teatro Estádio para o bairro, acenam com a possibilidade de construção de um trans-shopping de características culturais, gerando uma pendenga que se arrastou ao longo das duas últimas décadas. Esta luta tornouse paradigmática para o Teatro Oficina, instaurando-se em seu próprio processo de construçãoartística, metáfora materializada no heroísmo e na monumentalidade das várias partes que compõem a versão cênica de Os sertões, de Euclides da Cunha, considerada por José Celso como sua obra mais ambiciosa. A realidade da luta pela terra, expressa nos conflitos de Canudos, transcontextualizando-se na batalha pela conquista do espaço para a construção do Teatro Estádio: "Uma encenação num terreno dos impasses globais da contracenação entre um poder cultural

210 projeto prevê o desenvolvimento de atividades sócioculturais, voltadas para a população que circunda o teatro, excluída do exercício amplo de cidadania e de expressão cultural, quando da construção do Minhocão, que cortou o tradicional bairro italiano, conforme afirma José Celso Martinez Corrêa.

22 Corrêa, José Celso Martinez. Op. cit. nota 1: sem numeração.

23 Ibid.: sem numeração. 
direto e o vídeo financeiro que o cerca por todos os lados, o complexo do Baú da Felicidade", diz José Celso. ${ }^{23} \mathrm{O}$ impasse político aparece, literalmente, em A terra, primeira parte da encenação de Os sertões, no Teatro Oficina, realizada em 2003, inclusive com a apresentação no meio do espetáculo da maquete do Teatro Estádio.

No espetáculo, A terra, o caráter épico da primeira parte do livro de Euclides da Cunha, com a descrição geográfica do sertão de Canudos (topografia, rios, fauna, flora e os fenômenos atmosféricos climáticos), transformou-se numa narrativa cênica poético-musical operística, reunindo, além dos atores do grupo de José Celso, crianças e músicos, num grande coro, do qual o público também faz parte. Os próprios elementos cenográficos - panos e mangueiras representando rios, por exemplo - contribuem para o envolvimento quase "natural" da plateia, que é convidada a participar, desde o início, fazendo o aquecimento vocal com os atores e, ao longo do espetáculo ritualístico, dança, canta e reproduz falas.

Nessaatmosferacênico-vivencial,aterra do sertão de Canudos é, metaforicamente, representada por corpos nus e adereços, mas também pela relação concreta com a terra mesma do chão do espaço teatral escavada, pisoteada, enlameada, queimada $\mathrm{e}$, às vezes projetada em escala maior, com recursos de vídeo. A configuração da terra do sertão é ampliada para fora do espaço físico representacional, abarcando, além do "espaço-terreiro" do Teatro Oficina, no Bexiga/Bela Vista, os morros do Rio de Janeiro e até a terra de Bagdá.E, desse modo, há brechas para a encenação do conflito que envolve a posse do espaço/entorno do Teatro Oficina e o Grupo Sílvio Santos; a discussão sobre o poder do narcotráfico nas favelas cariocas (com o público todo sendo levado a gritar palavras de ordem pela legalização das drogas); e a Guerra de Bush contra o Iraque.

Aos aspectos do espetáculo hapenning (um espaço de vivência lúdica e coletiva) que poderíamos chamar "modernistas", soma-se a linguagem contemporânea da concepção cênica de José Celso, com o uso de recursos tecnológicos sofisticados de luz e som, incluindo a projeção de imagens da terra e de fragmentos textuais com várias formas de menção à escrita euclidiana.

A plateia, massivamente muito jovem (os atores também), se coloca no espaço completamente disponível, sujeita ao contato com a terra, a lama, a chuva de areia e a nudez dos corpos. Regendo o espetáculo, José Celso, na figura do beato Antônio Conselheiro, atua como um corifeu em (lindas) canções solo, a dar sentido político ao todo do espetáculo. Espetáculo este que age, profundamente, no sentido do estilhaçamento dos limites espaciais, temporais e narrativos do teatro, para a fúria dos que não suportam o caráter interativo de sua concepção e sua monumental duração de cinco ou seis ou sete horas. Ou para o êxtase dos que se deixam contagiar pela força telúrica das imagens e pela ruptura com a recepção passiva.

A aventura heróica do encenador tropicalista/oswaldiano demonstra as possibilidades de materialização do pensamento artístico antropofágico, no teatro contemporâneo. A vocação formal do espaço físico do Teatro Oficina enquanto uma passarela carnavalesca é explorada intensamente e reitera seu potencial para atravessar o paredão que o separa do espaço externo, para a concretização da ágora, do Teatro Estádio, apoteótico sonho de Oswald/Zé Celso.

Nesse sentido, mais um capítulo do conflito que envolve o terreiro eletrônico e o estacionamento do baú da felicidade parece caminhar para um provável desfecho. Em 24 de junho de 2010, o Instituto do Patrimônio Histórico e Artístico Nacional (IPHAN) aprovou o projeto de tombamento do Teatro Oficina, que só era protegido em âmbito estadual. O documento, que tramitava desde 2003, estabelece parâmetros para a construção de obra de engenharia no terreno que circunda o prédio, proibindo a descaracterização da paisagem em torno 
do Teatro Oficina, o que restringirá as ambições empresariais do Grupo Silvio Santos. Ao que tudo indica, o desenlace dessa curva dramática ainda aguarda muitas peripécias. Que o deus Dioniso não descuide de enviar eflúvios. Evoé!

\section{Referências bibliográficas}

ANDRADE, Oswald de. O homem e o cavalo. São Paulo: Ed.Globo: Secretaria de Estado da Cultura, 1990.

. O rei da vela. São Paulo: Abril S.A., 1976. (Coleção Teatro Vivo).

- O santeiro do mangue e outros poemas. São Paulo: Ed.Globo, 1991.

Do teatro que é bom.... In: Ponta de Lança. São Paulo: Ed. Globo, 1991, p102-108. - Marco Zero I: a revolução melancólica. São Paulo: Globo, 1991.

A utopia antropofágica. Apêndice: A antropofagia ao alcance de todos, por Benedito Nunes. São Paulo: Globo, 1995. Associação Teat(r)o Oficina Uzyna Uzona. Primeira Versão do Programa de Arquitetura-Urbanismo e Gestão do Teatro Estádio. Disponível em: <www. teatroficina.uol.com.br>

BERNSTEIN, Ana.A crítica cúmplice:Décio de Almeida Prado e a formação do teatro moderno. São Paulo: Instituto Moreira Salles, 2005.

BLOCH, Arnaldo. O mundo come Oswald (entrevistacomJoséCelso Martinez Corrêa). O Globo, Rio de Janeiro, 22 de outubro de 2004. Segundo Caderno, p. 1.

CANDIDO, Antonio. Estouro e libertação In: Brigada Ligeira. São Paulo: Ed. UNESP, 1992, p.17-32.

CANDIDO, Antonio.Digressãosentimental sobre Oswald de Andrade In: Vários escritos. São Paulo: Ed. Pensamento, 1970.

CORRÊA, José Celso Martinez; GLASS, Verena; VIANA, Natália, et.al. Zé Conselheiro (entrevista). Caros Amigos (Edição de aniversário: 7 anos). São Paulo: Editora Casa Amarela: ano VIII, n. 85, p. 31 a 37, abril de 2004.
CORRÊA, José Celso Martinez; PONCIANO, Helio. A revolução dos clássicos (entrevista). São Paulo: Bravo, ano 8, n 90, p. 26-35, março de 2005.

COSTAFILHO,Joséda.Teatrocontemporâneo no Brasil: criações partilhadas e presença diferida. Rio de Janeiro: 7 Letras, 2009.

FREITAS, Nanci de. O homem e o cavalo: montagem e monumentalidade na estética teatral oswaldiana. Rio de Janeiro: Tese de doutorado defendida no programa de PósGraduação em Teatro, da Universidade Federal do Estado do Rio de Janeiro UNIRIO, 1997.

HUIZINGA, Johan. Homo Ludens. Tradução de João Paulo Monteiro. São Paulo: Perspectiva, 1999.

MACHADO, Cassiano Elek. 50 anos da morte de Oswald de Andrade. Folha de São Paulo, São Paulo, 22 de outubro de 2004. Ilustrada, p. E4.

SANTIAGO, Silviano. Sobre plataformas e testamentos. In: Ponta de Lança. 1991: p. 7-22. Teatro Oficina: Lina Bo Bardi/Edson Elito São Paulo, Brasil, 1980-1984. Textos: Lina Bo Bardi, Edson Elito e José Celso Martinez Corrêa. Lisboa: Editorial Blau; Instituto Lina Bo Bardi e P.M. Bardi, 1999. 